Hydrazides of glycine-containing

Leave this area blank for abstract info.

decasubstituted pillar[5]arenes: synthesis

and encapsulation of Floxuridine

Dmitriy N. Shurpik, Denis A. Sevastyanov, Pavel V. Zelenikhin, Evgenia V. Subakaeva, Peter J. Cragg,

Vladimir G. Evtugyn, Yury N. Osin, Ivan I. Stoikov

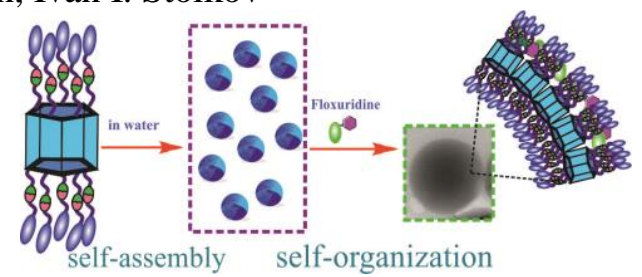


Tetrahedron Letters

journal homepage: www.elsevier.com

\title{
Hydrazides of glycine-containing decasubstituted pillar[5]arenes: synthesis and encapsulation of Floxuridine
}

\author{
Dmitriy N. Shurpik ${ }^{\mathrm{a}}$, Denis A. Sevastyanov ${ }^{\mathrm{a}}$, Pavel V. Zelenikhin ${ }^{\mathrm{b}}$, Evgenia V. Subakaeva ${ }^{\mathrm{b}}$, Peter J. \\ Cragg $^{\mathrm{c}}$, Vladimir G. Evtugin ${ }^{\mathrm{d}}$, Yuriy N. Osin ${ }^{\mathrm{d}}$ and Ivan I. Stoikov ${ }^{\mathrm{a}}{ }^{*}$ \\ ${ }^{a}$ Kazan Federal University, A.M. Butlerov Chemistry Institute, 420008 Kremlevskaya, 18, Kazan, Russian Federation \\ ${ }^{b}$ Institute of Fundamental Medicine and Biology, Kazan Federal University, 420008 Kremlevskaya, 18, Kazan, Russian Federation \\ ${ }^{c}$ School of Pharmacy and Biomolecular Sciences, University of Brighton, Huxley Building, Moulsecoomb. Brighton, East Sussex BN2 4GJ, UK \\ ${ }^{d}$ Interdisciplinary Centre for Analytical Microscopy, Kazan Federal University, 420008 Kazan, Kremlevskaya 18, Russian Federation
}

\section{ARTICLE INFO}

\section{ABSTRACT}

\section{Article history:}

Received

Received in revised form

Accepted

Available online

\section{Keywords:}

pillar[5]arene

self-assembly

TEM

macrocyclic receptors

Floxuridine

\begin{abstract}
Hydrazides of glycine-containing decasubstituted pillar[5]arenes were synthesized and characterized. Dynamic light scattering (DLS) and transmission electron microscopy (TEM) showed that self-assembly into monodisperse spherical nanoparticles $(28 \mathrm{~nm})$ was typical in water for pillarene hydrazides containing glycylglycide fragments $\left(1 \times 10^{-3} \mathrm{M}\right)$. Binding of the antitumor drug Floxuridine in water by the substituents of the macrocycle was established by NMR spectroscopy. It was shown by DLS and TEM, that heating of the macrocycle-Floxuridine system in a $1: 1$ ratio at $1 \times 10^{-4} \mathrm{M}$ led to its self-organization into monodisperse spherical particles $132 \mathrm{~nm}$ in diameter.
\end{abstract}

2009 Elsevier Ltd. All rights reserved.

\section{Introduction}

The problem of increasing efficacy of antitumor therapy has recently become acute due to the growth in the number of oncological diseases [1]. Surgical therapy, chemotherapy and immunotherapy are the main methods used in cancer treatment [2a] yet the high toxicity, low bioavailability, poor water solubility, low therapeutic indices, and non-targeted delivery of antitumor drugs to cancer cells remain the main disadvantages of antitumor therapy [2b]. In this regard, development of new watersoluble molecular capsules capable of increasing the solubility and reducing the toxicity of antitumor drugs is an urgent task for supramolecular chemistry to address [2c]. Supramolecular complexes based on such receptors can be applied to a number of problems related to bioavailability and targeted action of the therapeutic agents [2]. In the last decade [3], several macrocyclic structures have been developed and successfully incorporated in supramolecular drug delivery systems [4]. However, poor aqueous solubility, which significantly narrows the therapeutic window, remains a main problem in the application of macrocyclic hosts [3]. Amphiphilic macrocycles capable of association and aggregation are considered to be the main solution to the above problem [5]. Therefore, we propose to use water-soluble decasubstituted pillar[5]arene derivatives incorporating fragments of glycine. It is well known [6] that structural proteins such as elastin and collagen contain a high proportion of glycine residues and that collagen fibrils are components of the intercellular matrix which binds cells in tissues [6b]. In this work, we report the first example of the use of water-soluble pillar[5]arene derivatives containing peptide fragments as self-assembling biomimetic systems [7] for drug delivery.

Previously, we developed a technique [8] to introduce glycine fragments into the pillar[5] arene structure. Macrocycles $\mathbf{3}$ and $\mathbf{4}$ were obtained by hydrazinolysis, in yields of $78 \%$ and $82 \%$, respectively, from decaethers $\mathbf{1}$ and $\mathbf{2}$. Hydrazide fragments were employed as they may allow the target macrocycles to form additional intra- and intermolecular hydrogen bonds [6c]. The polarity of the amide groups and the ability to protonate the terminal amino groups will increase the solubility of the substituted macrocycles in water. 


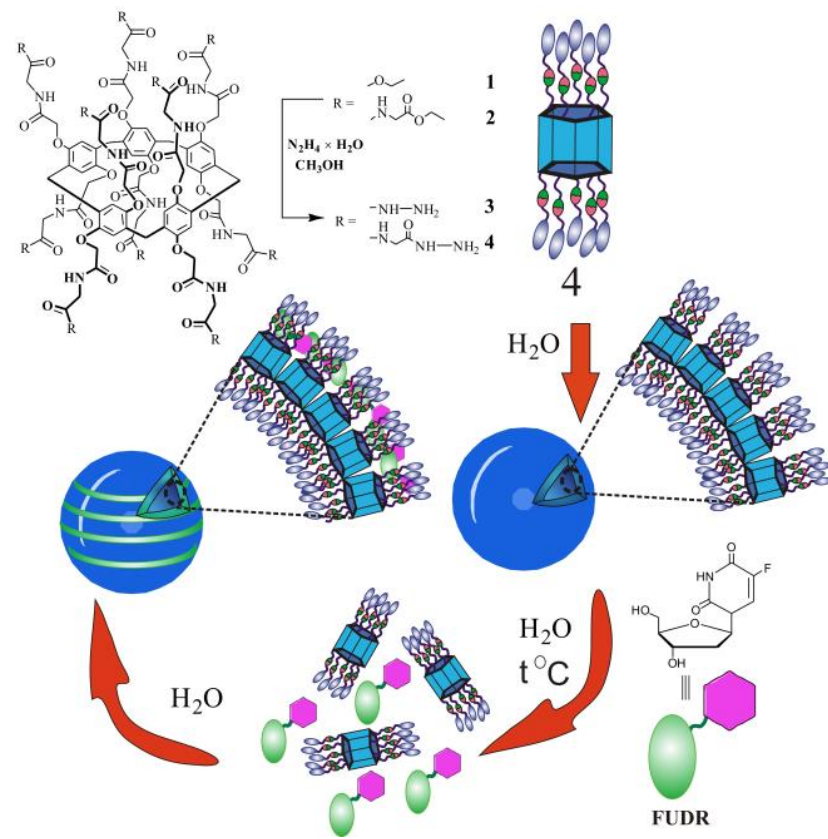

Figure 1. Synthesis of the macrocycles 3 and 4: the sketch represents pillar[5]arene 4 self-assembly and self-organization of the 4 / FUDR system into monodisperse spherical particles

The reactions were carried out in a 3:1 mixture of methanol / DMF at ambient temperature for 72 hours. Then self-association of macrocycles $\mathbf{3}$ and $\mathbf{4}$ and their aggregation with the antitumor drug 5-Fluorouracil (5-FU) and its derivative 5-fluoro-2'deoxyuridine (Floxuridine) (FUDR) were studied. These drugs are used to treat colorectal cancer, liver and stomach cancer [9], but their high toxicity causes a large number of side-effects, e.g. mouth ulcers, nausea, vomiting, hair loss, stomach ulcers, yellowing of the skin and eyes.

Self-association studies of macrocycles $\mathbf{3}$ and $\mathbf{4}$ were carried out in water using DLS. Introduction of ten acetohydrazide fragments, in the case of $\mathbf{3}$, appeared insufficient for dissolution of the macrocycle in water but the introduction of ten acetamidacetohydrazide fragments (4) led to formation of a homogeneous aqueous system. Macrocycle 4 self-associated in water in a concentration range of $1 \times 10^{-3}$ to $1 \times 10^{-5} \mathrm{M}$ with monodisperse associates $(\mathrm{PDI}=0.11$, hydrodynamic diameter of $27.5 \mathrm{~nm}$ ) were observed at $1 \times 10^{-3} \mathrm{M}$. According to the TEM data, self-associated aggregates of $\mathbf{4}$ were tightly packed and characterized by a spherical shape with an average particle diameter of $28 \mathrm{~nm}$ (Fig. 2a and 2c).

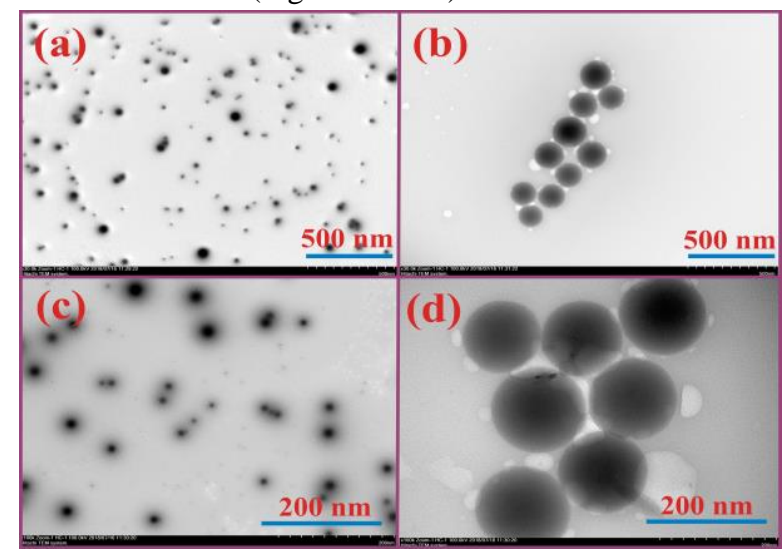

Figure 2. TEM images of pillar[5]arene 4 self-associated aggregates ((a) and (c)) and of pillar[5]arene 4 / FUDR associates ((b) and (d)) in water $\left(1 \times 10^{-3} \mathrm{M}\right)$. (a) and (b): $500 \mathrm{~nm}$ scale, (c) and (d): $200 \mathrm{~nm}$ scale.
The interaction of pillar[5] arene $\mathbf{4}$ with 5-FU and FUDR was studied by DLS, UV-vis and ${ }^{1} \mathrm{H},{ }^{13} \mathrm{C}, 2 \mathrm{D}$ NMR spectroscopy. No shifts of the absorption maxima were observed after the addition of the macrocycle 4 to 5-FU or FUDR by UV-vis spectroscopy. In the case of FUDR, a hypochromic effect in the region of 295 $\mathrm{nm}$ was found. The phenomena are complicated by light scattering, resulting in a rising baseline, making interpretation of the UV-vis data more difficult. This might be due to the aggregation of FUDR with pillar[5]arene 4.

The DLS investigations of the aggregates showed that a polydisperse system was formed from the 4 / FUDR system in ratios of 1:1, 1:5, 1:10, 5:1, and 10:1 over a concentration range of $1 \times 10^{-3}$ to $1 \times 10^{-5} \mathrm{M}$. However, monodisperse $(\mathrm{PDI}=0.11$ ) aggregates with a hydrodynamic diameter of $131.8 \mathrm{~nm}$ were formed for both compounds after $30 \mathrm{~min}$ of heating the 4 / FUDR system $\left(1: 1\right.$ ratio, $\left.\left.1 \times 10^{-4} \mathrm{M}\right)\right)$ at $50{ }^{\circ} \mathrm{C}(\mathrm{ESI})$. Thus, selforganization of the pillar[5]arene $\mathbf{4}$ with FUDR into monodisperse particles was observed only if the mixture was heated. With the concentration increased to $1 \times 10^{-3} \mathrm{M}$ and the ratio of the macrocycle 4 / FUDR changed to $1: 5,1: 10,5: 1$, and 10:1, the aggregate diameter increased to $268.8 \mathrm{~nm}$ and PDI sharply to 0.50 . A polydisperse colloidal system was formed at a concentration of $1 \times 10^{-2} \mathrm{M}$ for the 1:1 mixture of $\mathbf{4}$ and FUDR.

Unfortunately, the study of the interaction of macrocycle 4 with FUDR by ${ }^{1} \mathrm{H}$ NMR spectroscopy did not allow the nature of the interaction to be determined because of the changing position of the chemical shifts assigned to the guest and host. This is mainly due to signal overlap and broadening spectral lines from the formation of the association of macrocycle 4. Therefore, 2D ${ }^{1} \mathrm{H}-{ }^{1} \mathrm{H}$ NOESY NMR (Fig.3) and 2D DOSY spectroscopy and as ${ }^{19} \mathrm{~F}$ NMR spectroscopy of the antitumor drugs, alone and in mixtures with macrocycle $\mathbf{4}$ were used to confirm the formation of the associate.

Figure 3. The $2 \mathrm{D}{ }^{1} \mathrm{H}-{ }^{1} \mathrm{H}$ NOESY NMR spectrum of the 4 / FUDR complex $\left(1: 1,1 \times 10^{-3} \mathrm{M}\right)$ in $\mathrm{D}_{2} \mathrm{O}$ at $25^{\circ} \mathrm{C}$ and the proposed structure of the complex.

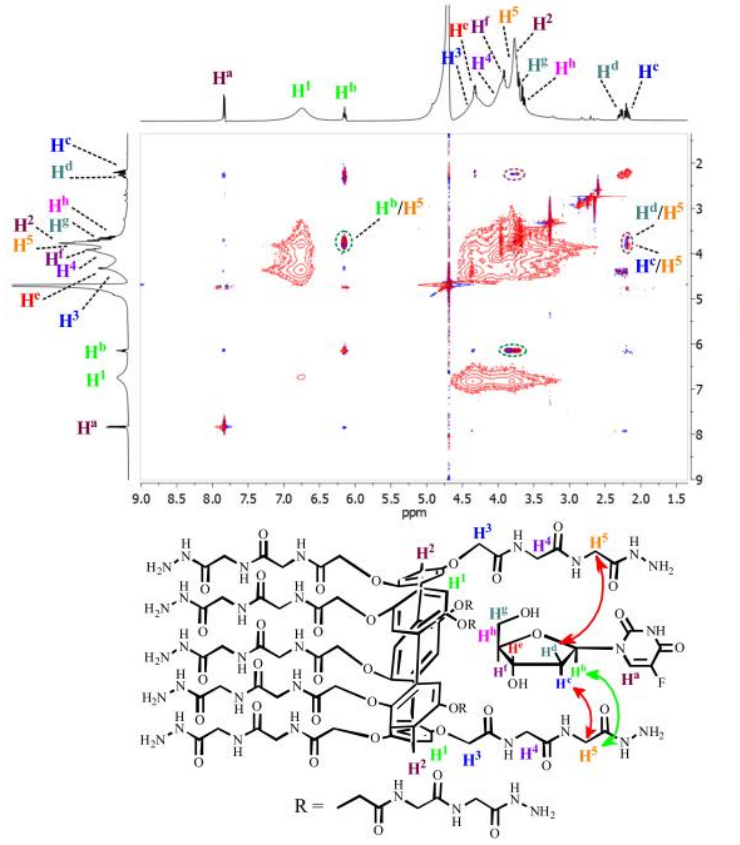

Cross-peaks between the $\mathbf{H}^{\mathbf{5}}$ protons (methylene groups of acetohydrazide fragments) of pillar[5] arene $\mathbf{4}$ and $\mathbf{H}^{\mathbf{b}}, \mathbf{H}^{\mathbf{d}}$ and $\mathbf{H}^{\mathbf{c}}$ protons of the deoxyribose fragment of FUDR were observed in the $2 \mathrm{D}{ }^{1} \mathrm{H}-{ }^{1} \mathrm{H}$ NOESY NMR spectrum of the $1: 1$ mixture of $\mathbf{4}$ and FUDR $\left(1 \times 10^{-3} \mathrm{M}\right)$ (Fig. 3). The formation of the 4 / FUDR 
associate was additionally confirmed by 2D DOSY spectroscopy (ESI). Diffusion coefficients of $1 \times 10^{-3} \mathrm{M} \mathrm{4,} \mathrm{FUDR} \mathrm{and} 4 /$ FUDR were determined at $298 \mathrm{~K}$ (ESI). The DOSY spectrum of the 1:1 mixture of $\mathbf{4}$ and FUDR $\left(1 \times 10^{-3} \mathrm{M}\right)$ showed the presence of only a single species of particles with a diffusion coefficient below that of the macrocyclic ligand $\mathbf{4}$ and the antitumor drug FUDR. A significant decrease in the diffusion rate of 4 / FUDR is an additional argument in favor of the formation of stable associates between $\mathbf{4}$ and FUDR.

According to the TEM data, associates of pillar[5]arene $\mathbf{4}$ with FUDR are characterized by a spherical shape and average diameter of $130 \mathrm{~nm}$ (Fig.2b and 2d.). No cross-peaks in the 2D ${ }^{1} \mathrm{H}-{ }^{1} \mathrm{H}$ NOESY NMR spectrum between the protons of macrocycle 4 and proton $(\delta=8.02 \mathrm{ppm})$ of the fluorouracil fragment in FUDR was observed. This made it possible to propose the formation of the associate due to hydrogen bonds between the fragments of deoxyribose in FUDR and the amide and hydrazide groups of the pillar[5]arene 4. The absence of significant displacements of the FUDR proton signals in the ${ }^{1} \mathrm{H}$ NMR spectrum indicated that the substrate molecules did not enter the hydrophobic cavity of the macrocycle 4 [10a]. Studying the ${ }^{19} \mathrm{~F}$ NMR spectra with proton decoupling of 5-FU, FUDR and 4 / 5-FU and 4 / FUDR mixtures is a convenient way to confirm this hypothesis because 5-FU and FUDR molecules contain a single fluorine atom that is detected by ${ }^{19} \mathrm{~F}$ NMR spectroscopy. If 5-FU and FUDR molecules are included in the cavity of pillar[5] arene 4, the fluorine atom is shielded and its signal shifts to a strong field [10 b, c]. Study on the $\mathbf{4}$ / 5-FU system in a 1:1 ratio $\left(1 \times 10^{-3} \mathrm{M}\right)$ showed no displacement of the ${ }^{19} \mathrm{~F}$ signals vs. initial value of the fluorine signal of 5-FU ( $\Delta \delta \sim 0.02 \mathrm{ppm}$ ) (Fig. 4). However, in case of the $\mathbf{4}$ / FUDR system (1:1 ratio, $1 \times 10^{-3}$ M), the fluorine signal was shifted by $\Delta \delta \sim 1.30 \mathrm{ppm}$ (Fig.4) against that in free FUDR. Based on this, it can be concluded that the downfield shift of the fluorine signal in the system of 4 / FUDR indicates no inclusion of the FUDR molecule in the cavity of the macrocycle 4 . De-shielding of the fluorine atom is caused by formation of the hydrogen bonds of the deoxyribose moiety and fluorine atom with the amide groups of pillar[5]arene 4.

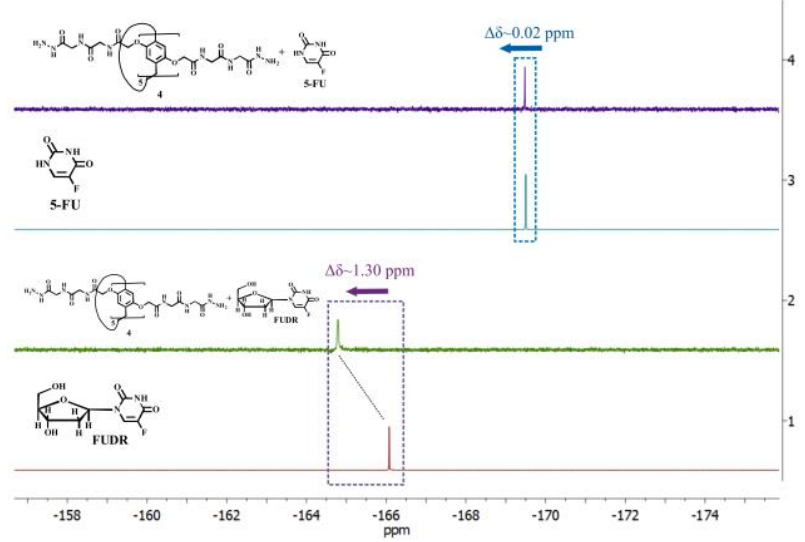

Figure 3. ${ }^{19} \mathrm{~F}$ NMR spectra with proton decoupling $\left(1 \times 10^{-3} \mathrm{M}\right)$ in $\mathrm{D}_{2} \mathrm{O}$ at $25{ }^{\circ} \mathrm{C}$ : 1) FUDR; 2) 4 / FUDR in the $1: 1$ ratio; 3) 5-FU; 4) 4 / 5-FU in the $1: 1$ ratio.

Further confirmation of this hypothesis was found in the additional study of the $2 \mathrm{D}{ }^{1} \mathrm{H}-{ }^{1} \mathrm{H}$ NOESY NMR spectrum of the 1:1 mixture of $\mathbf{4}$ and deoxyribose $\left(1 \times 10^{-3} \mathrm{M}\right)$ (ESI). Cross-peaks between protons $\mathbf{H}^{5}, \mathbf{H}^{4}$ and $\mathbf{H}^{3}$ (the methylene groups of acetohydrazide and acetamide fragments) of pillar[5]arene $\mathbf{4}$ and the deoxyribose protons in the 2D 1H-1H NOESY NMR spectrum of the $1: 1$ 4/deoxyribose mixture $\left(1 \times 10^{-3} \mathrm{M}\right)$ undoubtedly indicate formation of the 4 /deoxyribose associate by intermolecular hydrogen bonds between amide fragments of pillar[5]arene $\mathbf{4}$ and deoxyribose protons. The orientation of the FUDR molecule inside pillar[5]arene $\mathbf{4}$ was studied by computational methods and found to be in agreement with the NMR interpretation (ESI).

A series of experiments to assess the viability of cells under treatment with pillar[5]arenes $\mathbf{3}$ and $\mathbf{4}$ was carried out. Survival was determined after incubation of the cells with the pillar[5]arenes for 24, 48 and $72 \mathrm{~h}$. In the samples, cells survival was expressed in relative units against the control with no pillar[5]arenes. In the study of compound $3(25$ and $50 \mu \mathrm{g} / \mathrm{ml})$, an appropriate amount of deionized water was added to the control. Compound $\mathbf{3}$ appeared to be more toxic than $\mathbf{4}$ with a decreased survival at a concentration of $25-50 \mu \mathrm{g} / \mathrm{ml}$. Pillar[5]arene $4(250$ and $500 \mu \mathrm{g} / \mathrm{ml})$ was non-toxic throughout the $24 \mathrm{~h}$ treatment. A small concentration-dependent viability suppression was found for incubation times of $48 \mathrm{~h}$ and $72 \mathrm{~h}$. In general, the toxicity of $\mathbf{4}$ is weak even at high concentration (ESI).

In conclusion, water-soluble decasubstituted pillar[5]arenes containing hydrazide fragments of glycine and glycylglycine were synthesized for the first time. DLS showed that $1 \times 10^{-3} \mathrm{M}$ pillar[5]arene 4 containing acetamidacetohydrazide fragments formed monodisperse associates in aqueous solution with a PDI of 0.11 and a hydrodynamic diameter of $27.5 \mathrm{~nm}$. Association of macrocycle 4 with the antitumor drug 5-fluoro-2'-deoxyuridine (FUDR) was demonstrated by DLS, UV-vis and ${ }^{1} \mathrm{H},{ }^{13} \mathrm{C}, 2 \mathrm{D}$ NMR spectroscopy. As a result of 1:1 association, monodisperse nanosized particles with a PDI of 0.11 and a hydrodynamic diameter of $131.8 \mathrm{~nm}$ at $1 \times 10^{-4} \mathrm{M}$ were formed by both compounds. The formation of nano-sized particles with a diameter of $130 \mathrm{~nm}$ was shown by TEM. The formation of the 4 / FUDR associates occurred as "head to head" species with the fluorine atom directed towards the macrocyclic cavity of the pillar[5] arene and the deoxyribose FUDR fragment outwards as followed from the $2 \mathrm{D}{ }^{1} \mathrm{H}-{ }^{1} \mathrm{H}$ NOESY and ${ }^{19} \mathrm{~F}$ NMR spectroscopy.

\section{Acknowledgments}

The study was funded by RFBR according to research project № 18-03-00315. The authors are grateful to the staff of the Spectral-Analytical Center of Shared Facilities for Study of Structure, Composition and Properties of Substances and Materials of the A.E. Arbuzov' Institute of Organic and Physical Chemistry of the Kazan Scientific Center of the Russian Academy of Sciences for their research and assistance in discussion of the results. The study on the spatial structure of the compounds by NMR spectroscopy was funded by a subsidy of the Russian Government Program of Competitive Growth of Kazan Federal University among the World's Leading Academic Centers.

\section{References and notes}

1. (a) Lewis, J. D.; Scott, F. I.; Brensinger, C. M.; Roy, J. A.; Osterman, M. T.; Mamtani, R.; Bewtra, M.; Chen, L.; Yun, H.; Curtis, J. R. Am. J. Gastroenterol. 2018, 113, 405-417; (b) Hidai, C.; Kitano, H. Diseases. 2018, 6, 57-69; (c) Ahmed, M.; Chaudhari, K.; Babaei-Jadidi, R.; Dekker, L. V.; Nateri, A. S. Stem Cells. 2017, 35, 839-850.

2. (a) Masood, F. Mater. Sci. Eng., C. 2016, 60, 569-578; (b) Singh, R.; Lillard, Jr. J. W. Exp. Mol. Pathol. 2009, 86 (3), 215-223; (c) Blanco, J. L. J.; Benito, J. M.; Mellet, C. O.; Fernández, J. M. G. J. Drug deliv. Sci. tec. 2017, 42, 18-37.

3. (a) Jie, K.; Zhou, Y.; Yao, Y.; Huang, F. Chem. Soc. Rev. 2015, 44, 35683587; (b) Cottet, K. Marcos, P. M.; Cragg, P. J. Beilstein J. Org. Chem. 2012, 
8, 201-226; (c) Iqbal, K. S.; Allen, M. C.; Fucassi, F.; Cragg, P. J. Chem. Commun., 2007, 38, 3951-3953; (d) Ma, X.; Zhao, Y. Chem. Rev. 2014, 115, 7794-7839.

4. (a) Ramasamy, T.; Ruttala, H. B.; Gupta, B.; Poudel, B. K.; Choi, H. G.; Yong, C. S.; Kim, J. O. J. Control Release. 2017, 258, 226-253; (b) Pushpalatha, R.; Selvamuthukumar, S.; Kilimozhi, D. J. Drug. Deliv. Sci. Tec. 2017, 39, 362-371.

5. (a) Zhang, H.; Liu, Z.; Zhao, Y. Chem. Soc. Rev. 2018, 47, 5491-5528; (b) Shurpik, D. N.; Padnya, P. L.; Evtugyn, V. G.; Mukhametzyanov, T. A.; Khannanov, A. A.; Kutyreva, M. P.; Stoikov, I. I. RSC Adv. 2016, 6 (11), 9124-9131; (c) Mostovaya, O. A.; Padnya, P. L.; Shurpik, D. N.; Vavilova, A. A.; Evtugyn, V. G.; Osin, Y. N.; Stoikov, I. I. Macroheterocycles. 2017, 10, 154-163; (d) Smolko, V.; Shurpik, D.; Evtugyn, V.; Stoikov, I.; Evtugyn, G. Electroanal. 2016, 28, 1391-1400; (e) Stoikova, E. E.; Sorvin, M. I.; Shurpik, D. N.; Budnikov, H. C.; Stoikov, I. I.; Evtugyn, G. A. Electroanal. 2015, 27, 440-449; (f) Burilov, V.; Valiyakhmetova, A.; Mironova, D.; Sultanova, E.; Evtugyn, V.; Osin, Y.; Katsyuba, S.; Burganov, T.; Solovieva, S.; Antipin, I. New J. Chem. 2018, 42, 2942-2951; (g) Nazarova, A. A.; Yakimova, L. S.; Klochkov, V. V.; Stoikov, I. I. New J. Chem., 2017, 41, 1820-1826.

6. (a) Murray, R. K.; Gurner, D. K.; Mayes P. A. Harper's biochemistry; London: Prenrice Hall International, 1996; (b) Nelson, D. L.; Lehninger A. L.; Cox M. M. Lehninger principles of biochemistry. Macmillan, 2008; (c) Xiao, T.; Wang, L. Tetrahedron Lett. 2018, 59, 1172-1182; (d) Lin, Q.; Fan, Y. Q.; Mao, P. P.; Liu, L.; Liu, J.; Zhang, Y. M.; Yao H.; Wei, T. B. Chem. Eur. J. 2018, 24, 777-783; (e) Lin, Q.; Fan, Y. Q.; Gong, G. F.; Mao, P. P.; Wang, J.; Guan, X. W.; Liu, J.; Zhang, Y.; Yao, H.; Wei, T. B. ACS Sustainable Chem. Eng. 2018, 6 (7), 8775-8781.

7. Sun, Y.; Zhang, F.; Quan, J.; Zhu, F.; Hong, W.; Ma, J.; Pang, H.; Sun, Y.; Tian, D.; Li, H. Nature commun. 2018, 9, 2617-2624.

8. Shurpik, D. N.; Padnya, P. L.; Basimova, L. T.; Evtugin, V. G.; Plemenkov, V. V.; Stoikov, I. I. Mendeleev Commun. 2015, 6, 432-434.

9. (a) Group, C. C. C. Br. Med. J. 2000, 321, 531-535; (b) Grem J. L. Invest. New Drug. 2000, 18, 299-313; (d) Ceilley R. I. J. Dermatol. Treat. 2012, 23 , 83-89.

10. (a) Cheng, M.; Wang, Q.; Cao, Y.; Pan, Y.; Yang, Z.; Jiang, J.; Wang, L. Tetrahedron Lett. 2016, 57, 4133-4137; (b) Weiss-Errico, M. J.; O’Shea, K. E. J. Hazard. Mater. 2017, 329, 57-65; (c) Weiss-Errico, M. J.; Ghiviriga, I.; O'Shea, K. E. J. Phys. Chem. B. 2017, 121, 8359-8366.

\section{Supplementary Material}

Supplementary data associated with this article can be found in the online version, at 